UNIVERSITY OF KENTUCKY

LEXINGTON. KENTUCKY 40506.0055

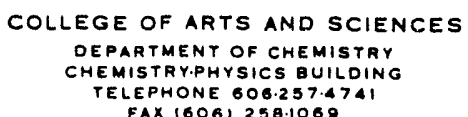

\section{MEMORANDUM}

TO:

Marilyn Keane

U. S. DOE Pittsburgh

$\mathrm{DOE} / \mathrm{PC} / 91291-\mathrm{T} 6$

John N. Augustine, Contract Specialist

DE93 009655

\title{
Kay Downey
}

Office of Technology Transfer

U. S. DOE Pittsburgh

From: Robert D. Guthrie

Principal Investigator for DE-FG22-91PC91291

I am sending to each of you a quarterly technical progress report representative of work accomplished as of December 31, 1992 .

cC: Dr. Karl Schroeder 
8ixth Report on Project DE-FG22-91PC91291

Report on Progress as of December 31, 1992

\section{Previous Work}

In earlier reports we have described our efforts to understand the mechanism of deuterium incorporation during the thermolysis of 1,2-diphenylethane and 2,2,5,5-tetramethyl-3,4-diphenylhexane under $D_{2}$ gas in a glass vessel. We have reported that in both of these cases, there is substantial deuterium incorporation. A summary of our conclusions follows.

Conclusions previously reported for the 1,2-diphenylethane (DPE) system.

1. Benzyl radicals produced in the thermolysis react mainly with DPE to extract a hydrogen atom and produce undeuterated toluene.

2. The 1,2-diphenylethyl radicals produced are mainly responsible for the reaction with $D_{2}$ to give $D$ atoms.

3. D atoms then react with aromatic rings to form adduct radicals which are, at least in part, reconverted to D-substituted aromatics in termination steps.

4. 2-Phenylethyl radicals react in a less discriminating manner, $1 / 3$ to $1 / 2$ of the events probably involving direct reaction with $\mathrm{D}_{2}$.

5. A reasonable match to major product distribution can be accomplished using a model consisting of the set of ten reactions 
described in our previous report as Figures 1 and 3 (Fifth Report, $10 / 31 / 93)$

We have submitted a preprint covering part of the results obtained with DPE for presentation at the Fuel Chemistry Division Symposium as part of the March 28 - April 2, 1993 Meeting of the American Chemical Society in Denver. A copy of this preprint is attached.

Conclusions previously reported for the $2,2,5,5$-tetramethyl-3,4diphenylhexane (TMDH) system.

1. TMDH undergoes thermolytic scission of its central $(3,4) \mathrm{C}-\mathrm{C}$ bond at temperatures as low as $300{ }^{\circ} \mathrm{C}$ to equilibrate the meso- and d,1-isomers. Cleavage of the 2,3-bond may also be involved. 2. When the thermolysis is carried out under $D_{2}$, the phenyl-tertbutylmethyl radicals may abstract $D$ from $D_{2}$ to give deuteriumlabeled neopentylbenzene. Neopentylbenzene becomes the major product and contains about $50 \%$ of one atom of $D$ in the benzylic position and 20 to 308 of one atom of D in the aromatic ring. 3. Both stilbene and diphenylethane are formed in this reaction and contain approximately two atoms of $D$ per molecule. It was hypothesized that a mechanism exists for the hydrogen atom promoted reaction of TMDH to give stilbene and diphenylethane. A mechanistic hypothesis was presented in Figure 5 (Fifth Report, $10 / 31 / 92)$

\section{DISCLAIMER}

This report was prepared as an account of work sponsored by an agency of the United States Government. Neither the United States Government nor any agency thereof, nor any of their employees, makes any warranty, express or implied, or assumes any legal liability or responsibility for the accuracy, completeness, or usefulness of any information, apparatus, product, or process disclosed, or represents that its use would not infringe privately owned rights. Reference herein to any specific commercial product, process, or service by trade name, trademark, manufacturer, or otherwise does not necessarily constitute or imply its endorsement, recommanufacturer, or otherwise doe United States Government or any agency thereof. The views and opinions of authors expressed herein do not necessariily staic or refiect those of the United States Government or any agency thereof. 


\section{Work in Progress}

Synthesis of Deuterium-Labeled Compounds. For some time, we have been attempting to prepare specifically deuterium-labeled DPE. Several unsuccessful approaches have been tried. A particularly interesting failure was the reaction of benzylmagnesium chloride with benzyl bromide. When benzyl- $\underline{\mathrm{d}}_{5}$ bromide was allowed to react with unlabeled benzylmagnesium chloride, the DPE produced contained substantial amounts of unlabeled material along with the desired DPE- $\underline{d}_{5}$ but very little $D P E-\underline{d}_{10}$. We tried some modifications, such as using cuprates, without any significant improvement. As the interpretation of our planned thermolysis experiments with labeled material would have been confounded by the presence of unlabeled material, the obtained synthetic outcome was unsatisfactory. We have given up on this approach but may come back someday to a study of the mechanism of this reaction.

We have now found an approach which does work, and this is outlined in Figure 1. The critical step is the reaction of 2phenylethyl choride with benzene in a Friedel-craft reaction. 1 We had worried that the label might be scrambled under the reaction conditions, but this does not appear to be a problem. We have thus made 1,1-dideutero-1,2-diphenylethane. GC/MS and NMR data shows that this the label comes through the Friedel-crafts procedure unscrambled.

We plan to now carry out the thermolysis of this compound under $\mathrm{N}_{2}$ and under $\mathrm{H}_{2}$. There are several issues which we hope to resolve with these experiments. Most critically, they will show 
that intramolecular deuterium scrambling under thermolysis conditions is not a problem for interpretation of earlier-reported results. We anticipate that in neither experiment will the aliphatic $D$ label be transfered to the aromatic ring. Secondly, we will find out the extent to which the diphenylethane cleavage is reversible. Reversible cleavage will give $\mathrm{DPE}-\underline{\mathrm{d}}_{4}$ and $\mathrm{DPE}-\underline{\mathrm{d}}_{0}$. Further, a comparison of deuterium content of the toluene produced in the $\mathrm{H}_{2}$ experiment with that in the $\mathrm{N}_{2}$ experiment will substantiate our conclusion that main course of reaction for the benzyl radical is to remove hydrogen from DPE. As shown in Figure 2 , the distribution of toluene- $\underline{d}_{0},-\underline{d}_{1},-\underline{d}_{2}$, and $-\underline{d}_{3}$ produced should be initially the same in both experiments if most of the toluene is formed as proposed. Moreover, this being the case, we can determine an isotope effect for this process. Preliminary experiments using the synthesized material will commence shortly.

We will also use the synthetic approach of Figure 1 to prepare ring-labeled materials. We have prepared 1-(4'-bromophenyl)-2phenylethane and will treat this with Reike magnesium followed by $\mathrm{D}_{2} \mathrm{O}$ to obtain the $4^{\prime}$-deutero compound. ${ }^{2}$ We anticipate that for this compound, the presence of $\mathrm{H}_{2}$ during the thermolysis will promote the transfer of $D$ atoms from aromatic to aliphatic sites, as predicted by the mechanistic scheme put forward in our earlier report.

Synthesis of $1,2,3,4$-tetraphenylbutane. We have also completed the synthesis of $1,2,3,4$-tetraphenylbutane (TPB). We 
followed the synthetic procedure of wyman. ${ }^{3}$ The yield from this procedure is low, but several alternative approaches have not worked any better. Preliminary experiments on the thermolysis of this compound in the presence of $D_{2}$ show that the major product is DPE as expected. Determination of the extent and location of deuterium incorporation is in progress.

Further Results with 2,2,5,5-Tetramethyl-3,4-diphenylhexane (TMDH). Some additional data has been added to that included in our last report. Previously presented tables are expanded below.

Table I. Deuterium Distribution in 1-Pheny1-2,2-dimethylpropane Formed from Thermolysis of TMDH under $D_{2}$ at $350^{\circ} \mathrm{C}$ (from GC/MS)

\begin{tabular}{lllll}
\hline Time $(\min )$ & $d_{0}$ & $d_{1}$ & $d_{2}$ & $d_{3}$ \\
\hline 5 & 38 & 51 & 11 & - \\
10 & 39 & 46 & 13 & 2 \\
20 & 40 & 47 & 11 & 3 \\
30 & 31 & 51 & 15 & 2 \\
40 & 33 & 50 & 15 & \\
\hline
\end{tabular}


Table II. Deuterium Incorporation in 1-Phenyl-2,2-dimethylpropane Formed from Thermolysis of TMDH under $D_{2}$ at $350{ }^{\circ} \mathrm{C}$.

\begin{tabular}{ccccc} 
Time (min) & $\begin{array}{c}\text { D/molecule } \\
(\text { GC/MS })\end{array}$ & $\begin{array}{c}\text { D/molecule } \\
(\text { NMR })\end{array}$ & $\begin{array}{c}\text { Aliphatic D } \\
\text { (1-position) }\end{array}$ & Aromatic D \\
\hline 5 & 0.73 & 0.86 & 0.53 & 0.33 \\
10 & 0.78 & $?$ & 0.50 & 0.28 \\
20 & 0.74 & & & \\
30 & 0.89 & 0.86 & 0.55 & 0.31
\end{tabular}

Table III. Deuterium Incorporation in 1,2-Diphenylethane Formed from Thermolysis of TMDH under $\mathrm{D}_{2}$ at $350^{\circ} \mathrm{C}$.

\begin{tabular}{|c|c|c|c|c|c|}
\hline Time & $(\min )$ & $\begin{array}{r}D / \text { molecule } e^{a} \\
(G C / M S)\end{array}$ & $\begin{array}{c}\mathrm{D} / \mathrm{molecule} \\
\text { (NMR) }\end{array}$ & Aliphatic D & Aromatic D \\
\hline & 5 & $?$ & 2.04 & 0.44 & 1.60 \\
\hline & 10 & $?$ & 1.98 & 0.67 & 1.31 \\
\hline & 20 & 1.5 & & & \\
\hline & 30 & 1.8 & & & \\
\hline & 40 & 1.6 & 3.37 & 1.55 & 1.82 \\
\hline
\end{tabular}

a Because the amount of DPE formed was small, it was difficult to get reliable data. A good mass spectral analysis was produced only in the 20 min run. The distribution for this run was $d_{0}=22 \%, d_{1}$ $=32 \%, \mathrm{~d}_{2}=28 \%, \mathrm{~d}_{3}=13 \%, \mathrm{~d}_{4}=4 \%$. The 30 and $40 \mathrm{~min}$ runs showed comparable distributions, but the experimental error was judged to be rather large. 
Table IV. Deuterium Incorporation in stilbene Formed from Thermolysis of TMDH under $\mathrm{D}_{2}$ at $350^{\circ} \mathrm{C}$.

\begin{tabular}{|c|c|c|c|}
\hline Time & $(\min )$ & $\begin{array}{l}\text { D/molecule } \\
\text { highest mass } \\
\text { GC/MS }\end{array}$ & $\begin{array}{r}\mathrm{D} / \mathrm{molec} \\
(\mathrm{NMF}\end{array}$ \\
\hline & 5 & $d_{2}$ & 1.98 \\
\hline & 10 & $d_{3}$ & 2.02 \\
\hline & 20 & $d_{3}$ & \\
\hline & 30 & $?$ & \\
\hline & 40 & $d_{3}$ & \\
\hline
\end{tabular}

The parent ion for stilbene loses $H$ readily and it is difficult to calculate an exact distribution. We are working on this. At the present time, we can only say that there is a significant amout of $\mathrm{d}_{3}$ material present at 10,20 and $40 \mathrm{~min}$. There does not appear to be a very large increase in $D$ content between the 10 and 40 minute samples.

From the 5 min and 10 min runs shown in Tables I - IV, mesoand d, l-TMDH were isolated. Each showed 20 to $30 \%$ of one atom of D, located entirely in the aromatic rings. The formation of Dcontaining DPE and stilbene suggests that tert-butyl radicals are formed and we have, in fact, found small amounts of products which appear to have added tert-butyl groups to the aromatic rings present. We have recently carried out a set of reactions at 325 ${ }^{\circ} \mathrm{C}$ and find the amount of DPE formed to be somewhat lower under these conditions. It seems possible that DPE may be formed from stilbene, even though we had earlier shown that stilbene is not significantly converted to DPE by $D_{2}$ under somewhat nore vigorous conditions. We are awaiting analysis of the product:s from these more recent experiments. 
Preparation of 1,2-Diphenyl-3,3-dimethylbutane. A logical product of the reaction of TMDH is 1,2-dipheny1-3,3-dimethylbutane, the product of loss of one tert-butyl group. We observe a GC peak of approximately the correct retention time, but the MS does not show the proper parent ion. We are synthesizing this compound following a literature procedure. 4 We will use this to determine whether it is a reaction product and also, determine its fate under conditions where TMDH reacts.

Mechanistic Diagnosis. It is clear that the TMDH reactions has some distinct mechanistic differences from the DPE case. In the DPE case, most of the initially formed toluene contains no deuterium. With TMDH, the neopentylbenzene contains only 30 to $40 \%$ $d_{0}$ material from the outset. We have shown that neopentylbenzene is inert if heated by itself with $D_{2}$, so it is necessary to postulate some intermediate which either contains or picks up deuterium atoms on its way to neopentylbenzene. 1-Phenyl-2,2dimethylpropyl (phenylneopentyl) radical is the logical intemediate. It seems almost necessary to postulate that this radical forms in order to explain the formation of $d, 1-T M D H$ under the reaction conditions. The phenylneopentyl radical apparently builds up to substantial levels in the reaction mixture because it can couple to give d,l-TMDH. One must guess that it also can remove $D$ atoms from $D_{2}$. When this happens, the resultant free $D$ atoms presumeably react with aromatic rings. 
In our previous report, we had argued that the formation of stilbene was promoted by a reaction with $D$ atoms. We are no longer certain about this proposal. Noting that stilbene is also formed in the vacuum thermolysis of this compound in comparable amounts, it may be that the formation of stilbene is a more or less independent process. Our previous proposal was based on the relatively large amount of $D$ in the stilbene. However, we are no longer certain about the $D$ levels in the stibene and, moreover, there are other ways to explain the phenomenon if it turns out to be real. It may, for example, turn out that stilbene is a good scavenger of $D$ atoms (either free or bound as aromatic ring adducts) and that, once formed, tends to accumulate $D$ and, probably, to give bibenzyl.

In our previous report, we presented a speculative mechanism for the conversion of TMDH to stilbene (Figure 5 in Fifth Report, 10/31/93). While it remains an interesting possibility, it now seems less likely that it is required to explain our results and that the simple process of Figure 4 (Fifth Report) will accomodate most of our observations. The main problem with the simple mechanism is that it predicts somewhat more D incorporation than is actually observed (75\% of the neopentylbenzene should contain benzylic D. However this could be accomodated by allowing termination to occur between tert-butyl radicals (generated from thermolysis of TMDH) and phenylneopentyl radicals as shown in Figure 3 which is a modification of our earlier proposal. We will attempt to model this sequence, then apply testing procedures. 
It looks as if it would be fairly simple to prepare TMDH with both para-positions blocked, probably by tert-butyl groups. There are reasons to believe that this would increase the yield in synthesis of the starting compound and would interfere with the formation of ring adducts. The effect of this modification on the pattern of deuterium incorporation would be instructive.

\section{References}

1. Ichii, M. Bull. Chem. Soc. Jpn., 1972, 45, 2810-2813.

2. Rieke, R. D.; Bales, S. E. J. Am. Chem. Soc. 1974, 96, 11751181 .

3. Wyman, D. P. J. Org. Chem. 1962, 27, 3712. See also, Brook, A. G.; Tai, K. N.; Gilman, H. J. Am. Chem. Soc. 1955, 77, 6219, and Smith, L. I.; Hoehn, H. H. J. Am. Chem. Soc. 1911, 63, 1184 .

4. Clin, B.; Jousseaume, B.; Duboudin, J.-G. Bull. Soc. Chim. Fr. 1974, 1293-1296. 
Figure 1. Synthesis of Deuterium-Labeled DPE
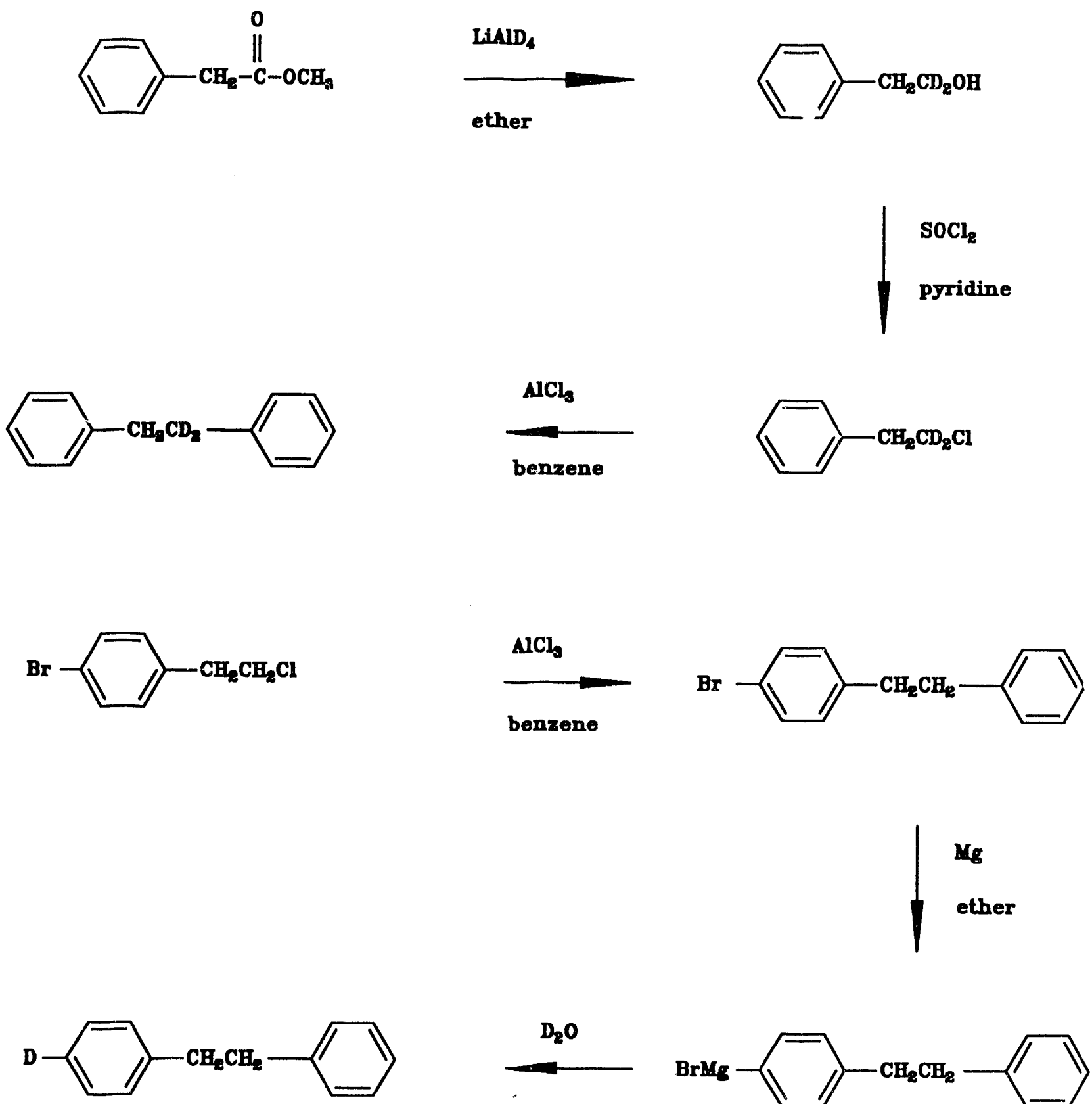<smiles>CC(C)(Cc1ccccc1)c1ccc(CCCc2ccccc2)cc1</smiles> 


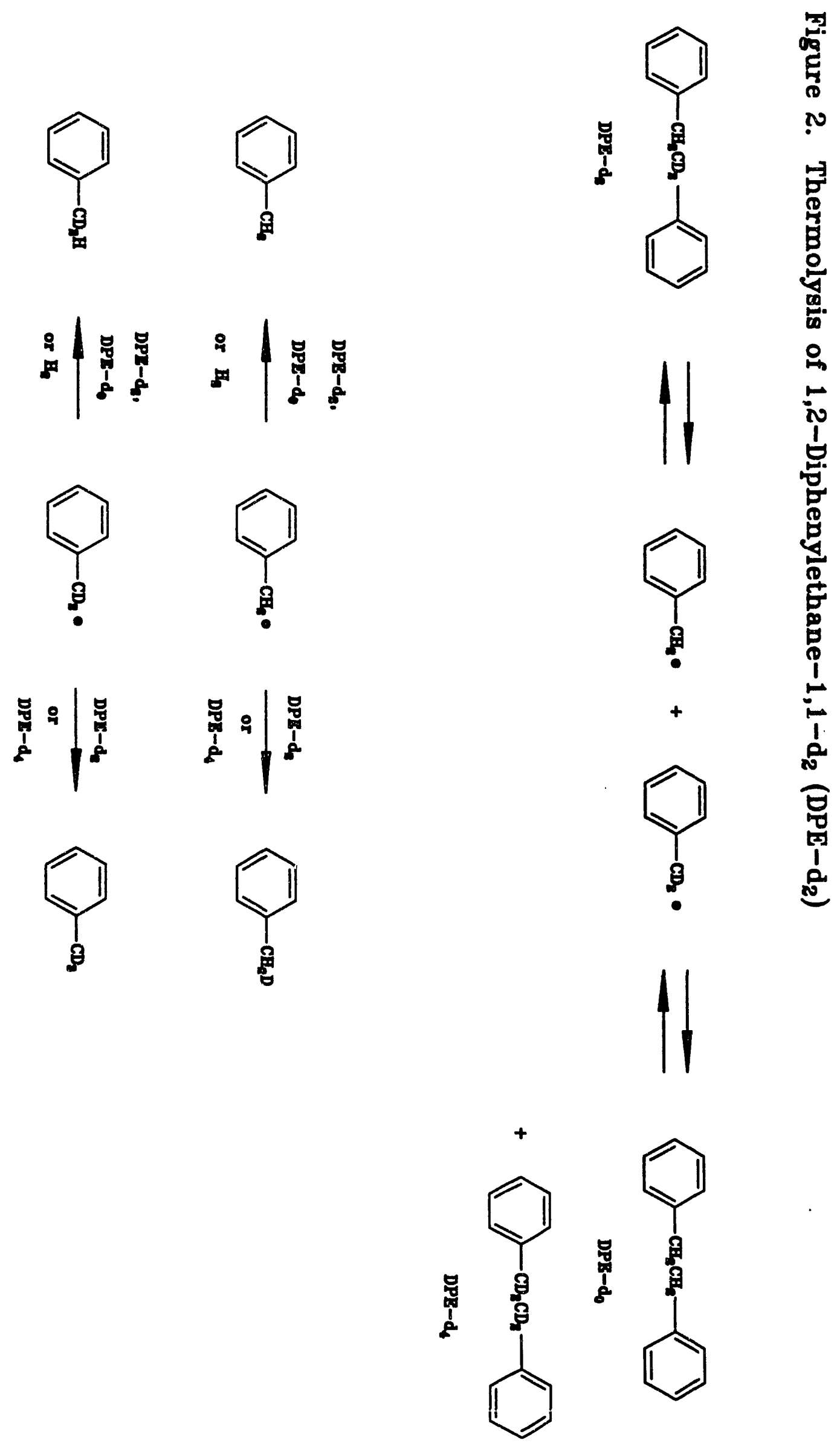




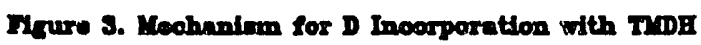
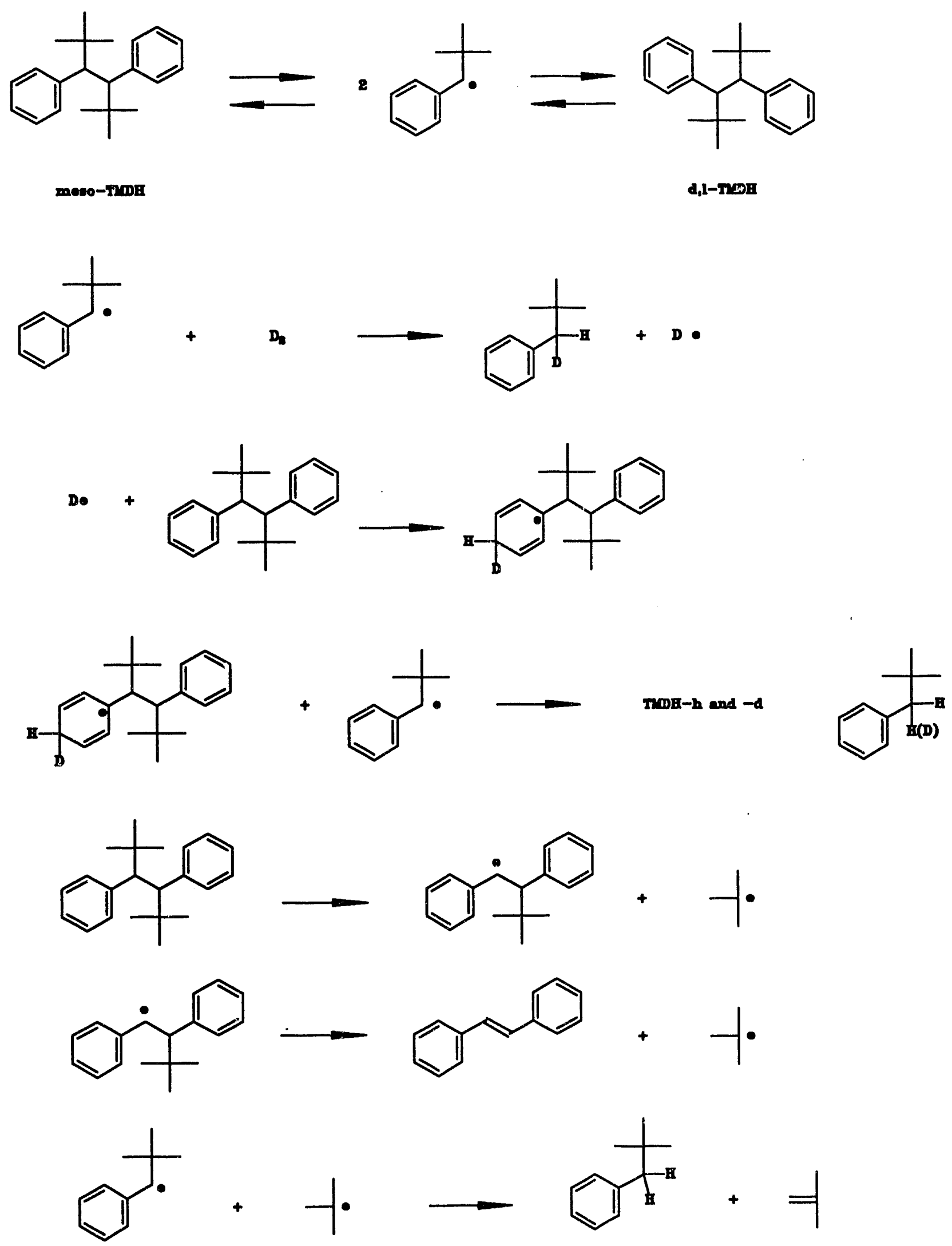


\title{
PROMOTION OF DEUTERIUM IACORPORATION FROM $D_{2}$ INTO COAL MODEL COMPOUNDS BY BENZYIIC RADICALS
}

\author{
Robert D. Guthrie \\ Buchang Shi \\ Rustem Sharipov \\ Department of Chemistry \\ University of Kentucky \\ Lexington, KY 40506
}

\begin{abstract}
Burtron H. Davis
Kentucky Center for Applied Energy Research

3572 Iron Works Pike, Lexington, KY 40511
\end{abstract}

Keywords: $D_{2}$, hydroliquefaction, diphenylethane

\section{INTIRODUCTION}

A large number of revealing mechanistic investigations have been carried out dealing with the thermolysis of coal and compounds which model its structure. Perhaps because of experimental difficulties, much less attention has been given to the reaction with molecular hydrogen. It seems fair to say that the detailed mechanism by which molecular hydrogen, separately or in combination with "donor solvents", is able to effect the reductive simplification of coal is not completely understood. An obvious approach to following the reaction with $\mathrm{H}_{2}$ is to substitute $\mathrm{D}_{2}$. The literature contains ample evidence that deuterium is incorporated into reaction products when thermolysis of coal and coal models is carried out under $D_{2}$ gas. ${ }^{1}$ It has also been shown that D-labeled substrates, such as tetralin-d ${ }_{12}$, transfer $D$ atoms back to dihydrogen such that HD is produced from $\mathrm{H}_{2}{ }^{2}$

Similarly it is clear that once incorporated into a molecule of organic substrate, transfer of $D$ atoms between molecules is often facile. ${ }^{3}$ Several mechanisms can be involved in the scrambling process. Molecule-induced homolysis and symmetry-allowed, pericyclic mechanisms have been documented by Brower and Pajak. ${ }^{4}$ A demonstration of radical-promoted exchange was provided by King and Stock $^{5}$ who showed that the presence of species which undergo facile homolysis increases the rate of transfer of deuterium between benzylic positions in different molecules. The mechanisms suggested seem reasonable, however, most of the proposed schemes do not address the question of how the initial transfer from $\mathrm{H}_{2}$ occurs.

The facility of the scrambling reactions makes the question of how the hydrogen is transferred from $\mathrm{H}_{2}$ gas into the coal structure in the first place, a particularly difficult one to answer because the initial landing site of the hydrogen atoms is rendered uncertain. Because the $\mathrm{H}-\mathrm{H}$ bond is quite strong, this initial step would seem likely to be a major obstacle to the process of interest and slower than subsequent events. A scheme put forward by Vernon ${ }^{6}$ proposes hydrogen abstraction from H2 by benzyl-type radicals. This suggestion was later supported by Shin. ${ }^{7}$ Vernon's suggestion is based on the observation that the cleavage of 1,2-diphenylethane, DPE, gives an increased yield of benzene when the reaction is carried out under $\mathrm{H}_{2}$. The phenomenon is more pronounced when the reactions are run in the absence of a hydrogen atom donor (tetralin or 9,10-dihydrophenanthrene). It is suggested that benzyl radicals react with dihydrogen, producing toluene and 
hydrogen atoms. The hydrogen atoms thus generated are responsible for the hydrogenolysis of the DPE to give benzene. In the presence of hydrogen donor solvents, the benzyl radicals react to give toluene and the production of $\mathrm{H}$ atoms is reduced. The latter part of this scheme seems quite reasonable based on the observed facility of reaction between benzyl radicals and compounds with structures similar to donor solvents. ${ }^{8}$ Likewise, the reaction of hydrogen atoms with the aromatic ring of DPE seems reasonable both on energetic grounds and in consideration of the results of Price who showed that H-atoms generated in the thermolysis of toluene above $500{ }^{\circ} \mathrm{C}$ react with toluene to produce $\mathrm{CH}_{4}$ and $\mathrm{H}_{2}$ with nearly equal rates. The reaction between benzyl radicals and $\mathrm{H}_{2}$ seems the most uncertain part of the scheme in that the $\mathrm{C}-\mathrm{H}$ bond energy of toluene is $85 \mathrm{kcal} / \mathrm{mole}$ where as that of $\mathrm{H}-\mathrm{H}$ is $104 \mathrm{kcal} / \mathrm{mole}$. $^{10}$ The reaction of benzyl radical with dihydrogen to form toluene and hydrogen atoms is thus likely to have an activation enthalpy of more than $20 \mathrm{kcal} / \mathrm{mole}$. This would seem to make it an unlikely competitor with various other potential reactions of benzyl radicals which are possible in the system studied.

An additional uncertainty regarding these reactions, is that most of the reported exchange studies using $D_{2}$ as a source of deuterium had utilized metal reactor vessels. This raised the question of whether the initial process for introduction of $D$ atoms into the thermolysis milieu might be metal catalyzed. Either the walls of the reaction vessel or metal species contained in common reactor ves: el sealants are possible stopover points for $D$ atoms prior to their introduction at the seminal sites for the scrambling process. If these were involved, the well-precedented process of double bond reduction by metal-bound deuterium would then be a likely entry route for $D$ atoms. In cases where liquefaction is accomplished by the deliberate addition of hydrogenation catalysts, this would be the expected mechanism. ${ }^{11}$ As we wished to understand the noncatalyzed reaction and to use it as a base line for further studies of catalytic agents, we designed and employed a suitable glass reaction vessel.

\section{RE8ULTS AND DISCUS8ION}

Using the glass reactior vessel described in the experimental section, we have carried out the thermolysis of 1,2-diphenylethane, DPE, under 2000 psi of $D_{2}$ gas at $450^{\circ} \mathrm{C}$. DPE disappeared following a first order rate law as shown in Figure 1 . The resultant mixture showed products reported earlier by Poutsma ${ }^{12}$ for this reaction in the absence of $D_{2}$ : toluene, benzene, ethylbenzene, stilbene, 1,1-diphenylethane, phenanthrene and diphenylmethane. We also found what appeared to be diphenylpropane and trace amounts of other materials. For comparison, we carried out the reaction at the same pressure of $\mathrm{N}_{2}$ and found most of the same products except, as reported by Vernon, ${ }^{6}$ greatly reduced relative amounts of stilbene, benzene and ethylbenzene. These results are shown in Table $I$.

Representative GC\MS data on the mixture obtained from the $D_{2}$ reaction are shown in Table II. The data suggest that deuterium introduction is taking place both at aliphatic positjons and in the aromatic rings (note both benzene- $\underline{d}_{1}$ and $-\underline{d}_{2}$ are formed.) To assess the relative amounts of aromatic and aliphatic substitution, the reaction mixture was subjected to gas chromatographic separation and the individual components analyzed by both ${ }^{2} \mathrm{H}-\mathrm{NMR}$ and ${ }_{\mathrm{H}-\mathrm{NMR} \text {. Typical results are }}$ shown in Table III.

Interestingly, as seen in Table II, the pattern is very similar for 
deuterium distribution in toluene and DPE at low conversion. Later in the reaction, the amount of deuterium in DPE is significantly greater than in toluene. Surprisingly, despite the fact that hydrogen atoms must be supplied in order for DPE to be converted to toluene, the toluene formed at low conversions (in the 8 minute run, ca. $20 \%$ of the bibenzyl has been converted to products and about half of this is toluene) contains only about $20 \%$ of one atom of D by GC/MS. This can only mean that at least $80 \%$ of the benzyl radicals reacting to give toluene do so by removing $H$ atoms, presumably from DPE, rather than $D$ atoms from $D_{2}$. Moreover, the fact that at short reaction times, there is already a substantial amount of $D$ in the starting $D P E$, demands that at least some of the D-substituted toluene arises because it is formed from D-substituted DPE. This strongly suggests that DPE molecules can pick up $D$ atoms without first undergoing homolysis.

If this reasoning is correct, it suggests that the most prominent reaction of the $R^{\cdot}+D_{2} \rightarrow R-D+D^{-}$type, is that in which $R^{\cdot}=1,2-$ diphenylethyl radical rather than benzyl radical. This is somewhat surprising in that more highly-substituted radicals are normally viewed as being more stable and consequently less reactive. on the other hand, in the equilibration of species present during reaction conditions, the diphenylethyl radical will achieve higher concentration $^{13}$ which will compensate for its possibly lower reactivity. Further, results to be described later for a new substrate suggest that viewing more highly-substituted radicals as less reactive, may be an oversimplification.

It will be noted that the deuteration pattern for ethylbenzene as seen in Tables $I$ and II, is distinctly different from those of toluene and DPE. If, as is generally accepted, ethylbenzene is formed by the reaction of 2-phenylethyl radical with a hydrogen source, the results suggest that, being a more reactive radical, the 2-phenylethyl radical is less selective and therefore reacts directly with $D_{2}$ to a greater extent than do the more stable benzylic radicals present. Even after only $10 \%$ conversion of DPB, about $50 \%$ of the ethylbenzene molecules present contain deuterium. A similar situation exists for 1,1diphenylethane which is believed to arise from 2,2-diphenylethyl radical, believed to be formed by rearrangement. ${ }^{2}$ (See Table II.) Unfortunately, we have not yet been able to get reliable GC\MS data for benzene at low conversion because of the problem of getting it cleanly separated from solvent on the GC. We are still working on this.

It has been possible to isolate the more abundant products by preparative GC. We have then determined both ${ }^{2} \mathrm{H}$ and ${ }^{1} \mathrm{H}$ NMR spectra using $\mathrm{DCO}_{2} \mathrm{Me}$ as an internal standard for both spectra. This has allowed us to calculate the relative amounts of GC\MS-determined D atoms which are located at aliphatic vs aromatic sites. These data are shown in Table III for toluene, DPE and ethylbenzene. It is immediately apparent that deuterium is being incorporated at both aliphatic and aromatic sites. Moreover, the D-atom populations at the two types of location would appear to be similar in magnitude. This is consistent with a mechanism in which each aliphatic $D$ atom introduced via $R^{*}+D_{2} \rightarrow R-D+D^{*}$ results in D-atom incorporation in an aromatic ring. More detailed analysis of the recovered DPE suggests that the number of aromatic $D$ atoms exceeds the number of aliphatic $D$ atoms by a factor of between 1.2 and 1.5 (average $=1.4$ ). This would suggest that there is some mechanism for $D$ incorporation at aromatic sites which does not require an aliphatic radical precursor. There are a variety of possibilities, but one of the simplest is the displacement of $\mathrm{H}$ atoms by $\mathrm{D}$ atoms (probably a two step process such as reactions 4 and 9 in Figure 3). The $H$ atoms thus generated could then react with 
$D_{2}$ to generate more $D$ atoms. It is reasonable to expect that if $D$ atoms can displace alkyl radicals from the aromatic ring, the same can happen for $H$ atoms with a five to one statistical advantage. Seeing that the amount of ethylbenzene produced is roughly $10 \%$ of the total conversion, it is perhaps reasonable to find a substantial excess of D at aromatic sites.

By computer simulation, we have tried to match the product distribution (including deuterated products) using only the first 8 reactions shown in Figure 3. These account only for the introduction of deuterium into starting DPE and the formation of toluene. We felt if we could get close to an accommodation of the data with this simple scheme, we could then approach the full set of products by elaboration and fine tuning. It will be noticed that the reaction of benzyl radicals with molecular deuterium $\left(\mathrm{PhCH}_{2}{ }^{-}+\mathrm{D}_{2} \rightarrow \mathrm{PhCH}_{2} \mathrm{D}+\mathrm{D}^{-}\right)$has been omitted.

The assumption that only the reactions 1 through 8 are involved leads to the conclusion that the stoichiometry for formation of the major products should be between:

$5 \mathrm{PhCH}_{2} \mathrm{CH}_{2} \mathrm{Ph}+2 \mathrm{D}_{2} \rightarrow 2 \mathrm{PhCH}(\mathrm{D}) \mathrm{CH}_{2} \mathrm{Ph}+\mathrm{D}-\mathrm{PhCH}_{2} \mathrm{CH}_{2} \mathrm{Ph}+3 \mathrm{PhCH}_{3}+\mathrm{PhCH}_{2} \mathrm{D}$

and

$6 \mathrm{PhCH}_{2} \mathrm{CH}_{2} \mathrm{Ph}+2 \mathrm{D}_{2} \rightarrow 3 \mathrm{PhCH}(\mathrm{D}) \mathrm{CH}_{2} \mathrm{Ph}+\mathrm{D}-\mathrm{PhCH}_{2} \mathrm{CH}_{2} \mathrm{Ph}+4 \mathrm{PhCH}_{3}$

Eq (b) represents the limit in which reaction 2 (Figure 3 ) becomes so preferred relative to reactions 7 and 8 that all of the toluene formed arises via reaction 2 and thus would containing no D. Eq (a) results from the limit wherein reactions 5 and 6 become unimportant relative to reaction 3 thus maximizing the amount of $\mathrm{PhCH}_{2} \mathrm{D}$ produced. If reactions 5, 6, 7 and 8 all participate equally in consuming the adduct, then the intermediate stoichiometry of eq (c) should be found.

$11 \mathrm{PhCH}_{2} \mathrm{CH}_{2} \mathrm{Ph}+4 \mathrm{D}_{2} \rightarrow 5 \mathrm{PhCH}(\mathrm{D}) \mathrm{CH}_{2} \mathrm{Ph}+2 \mathrm{D}-\mathrm{PhCH}_{2} \mathrm{CH}_{2} \mathrm{Ph}+7 \mathrm{PhCH}_{3}+\mathrm{PhCH}_{2} \mathrm{D}$

Clearly none of these options nor any gradation in between can explain the observed facts. The observed ratio of $\mathrm{PhCH}_{2} \mathrm{D}$ and $\mathrm{PhCH}_{3}$ is not far from the stoichiometry of eq (c), but the experimentally observed ratio of aromatically deuterated DPE) to aliphatically deuterated DPE is found experimentally to be rather constant at a value of 1.4. The stoichiometries of eqs (a), (b), or (c) demand that the ratio be between 0.25 and 0.40 . Even if a huge isotope effect were assumed favoring reaction 5 over reaction 6 , the maximum possible ratio would be 1.0 .

Reactions 9 and 10 coupled with reaction 4 , constitute a kinetic chain sequence for the introduction of aromatic $D$ without producing aliphatically deuterated DPE. The stoichiometry of this sequence, taken in isolation from the other reactions is simply:

$$
\mathrm{PhCH}_{2} \mathrm{CH}_{2} \mathrm{Ph}+\mathrm{D}_{2} \rightarrow \mathrm{D}-\mathrm{PhCH}_{2} \mathrm{CH}_{2} \mathrm{Ph}+\mathrm{HD}
$$

It therefore seems that it should be possible to combine reactions 1 through 10 to approximately match the experimental data by selecting an appropriate set of relative rates. We are working on tilis proposition at the present time and preliminary results indicate that it will be possible to match the distribution of the major products. 
Reaction Procedure. The device shown in Figure 2 (a) consists of a thick glass reaction bulb with a long capillary neck. The reactor is inverted and several glass beads are added followed by solid reactants through the end opposite to the capillary. The reactor is sealed at the constriction Figure 2 (b). The vessel is then suspended in glass wool in the interior of a stainless steel reaction tube having a long neck to house the capillary section of the vessel. The entire apparatus is evacuated, pressured with $D_{2}$ gas, closed off and shaken at the desired temperature in a fluidized sand bath. When the reaction is complete, carbon disulfide is added and products removed for analysis using a long syringe needle. In the absence of gas generation within the tube, our observation has been that little or no material is lost from the interior of the bulb. Control experiments in which a hydrogenation cataiyst was deliberately added showed complete saturation of aromatic compounds under the reaction conditions.

\section{REFERENCES}

1. a. Skowronski, R. P. : Ratto, I. B.; Goldberg, I. B. : Heredy, L. A. Fuel $5984,63,440-448$. b. Ratto, J. J. ACS Fuel Chem. Preprints 1979, 24, 155. C. Goldberg, I. B.; Crowe, H. R.; Ratto, J. J.: Skowronski, P. R.; Heredy, L. A. Fuel 1980, 59, 133. d. Noor, N. S.: Gaines, A. F. Abbott, J. M. Fuel 1986, 65, 67-73. e. Kershaw, J. R.; Barrass, G. Fuel 1977, 56, 455 .

2. Cronauer, D. C.: McNeil, D. C.: Ruberto, R. G. Fuel 1982, 61, 610-619.

3. a. Franz, J. A.: Camaioni, D. M. Fuel 1984, 63, 213-229. b. Franz, J. A. Fuel 1979, 58 405-412. C. Aulich, T. R.; Knudson, C. L.; Hawthorne, S. B. preprints Div. of Fuel Chem. Am. Chem. Soc. 1988, 33, 368-379. d. Benjamin, B. M.; Douglas, E. C.; Mesmer, S. ibid. $1982,27,1-5$.

4. a. Pajak, J.; Brower, K. R. J. Org. Chem. 1986, 50, 2210-2216. b. Brower, KR.; Pajak, J. ibid., 1984, 49, 3970-3973.

5. King, H. H. ; stock, L. M. Fuel 1982, 61, 257-264.

6. Vernon, L. W. Fuel 1980, 59, 102.

7. Shin, S.-C.; Baldwin, R. M.; Miller, R. L. Energy and Fuels 1989, 3. 71-76.

8. Bockrath, B.; Bittner, D.; McGrew, J. J. Am. Chem. Soc. 1984, 106, 135-138.

9. Price, S. J. Can. J. Chem. 1962, 401310.

10. Benson, S. W. J. Chem. Ed. 1965, 42, 502.

11. a. Chien, P.-L.; Sellers, G. M.; Weller, S. W. Fuel Processing Technology 1983, 7, 1-9. b. Brammer, S. T.; Weller, S. W. ibid. 1979, $\underline{2}$, 155-159. C. Patxer, J. F.; Farrauto, R. J.; Montagna, A. A. Ind. Eng. Chem. Process Des. Dev, 1979, 18, 625-630. d. Davis, K. P.; Garnett, J. L. J. Phys. Chem. 1971, 75, 1175-1177. e. Davis, K. P.; Farnett, J. L.; O'Keefe, J. H. Chem. Communications 1970, 1672-1673. 
12. a. Poutsma, M. L.: Dyer, C. W. J. org. Chem. 1982, 42, 4903. b. Buchanan, A. C.; Dunstan, T. S. J.; Douglas, E. C.; Poutsma, M. L. J. Am. Chem. Soc. $1986,108,7703$.

13. Livingston, R.; Zeldes, H.; Conradi, M. S. J. Am. Chem. Soc. 1979, 101, 4312-4319.

Table I. Product Distribution in the Thermolysis of Diphenylethane at $450^{\circ} \mathrm{C}$ for 30 Minutes

Mole $q$ wt. $\%$ Mole $\%$ wto

Under $\mathrm{D}_{2}$ Under $\mathrm{D}_{2}$ Under $\mathrm{N}_{2}$ Under $\mathrm{N}_{2}$

$\begin{array}{lcccc} & & & & \\ \text { 1,2-Diphenylethane } & 23.5 & 36.6 & 36.1 & 47.1 \\ \text { Toluene } & 47.8 & 37.1 & 47.1 & 31.1 \\ 1,2,3,4-T r i p h e n y l b u t a n e & 0.25 & 0.8 & <0.1 & <0.1 \\ \text { Benzene } & 17.2 & 9.3 & 0.9 & 0.5 \\ \text { Ethylbenzene } & 8.6 & 7.7 & - & -- \\ 1,1-D i p h e n y l e t h a n e & 1.5 & 2.3 & 0.9 & 1.2 \\ \text { Stilbene } & 1.3 & 1.9 & 12.2 & 15.8 \\ \text { Phenanthrene } & 0.8 & 1.2 & <0.3 & <0.5 \\ \text { Triphenylpropane } & 0.8 & 1.8 & 0.7 & 1.9 \\ \text { Diphenylpropane } & 0.44 & 0.73 & -- & -- \\ \text { Diphenylmethane } & 0.36 & 0.52 & 1.4 & 1.7 \\ \end{array}$

Table II. Deuterium Distribution in Products from Thermolysis of Diphenylethane at $450{ }^{\circ} \mathrm{C}$ Under $D_{2}$

\begin{tabular}{|c|c|c|c|c|c|c|c|c|c|c|}
\hline \multirow[b]{2}{*}{ Compound } & \multicolumn{5}{|c|}{ After $8 \mathrm{~min}$} & \multicolumn{5}{|c|}{ After $30 \mathrm{~min}$} \\
\hline & $8 d_{0}$ & $f d_{1}$ & $f \mathrm{~d}_{2}$ & $8 d_{3}$ & $q d_{4}$ & $8 d_{0}$ & $8 d_{1}$ & $8 a_{2}$ & $8 d_{3}$ & $8 d_{4}$ \\
\hline \multicolumn{11}{|l|}{ 1,2-Diphenyl- } \\
\hline $\begin{array}{l}\text { ethane } \\
\text { Toluene }\end{array}$ & $\begin{array}{l}66 \\
78\end{array}$ & $\begin{array}{l}28 \\
20\end{array}$ & $\begin{array}{l}6 \\
2\end{array}$ & 1 & $\overline{-}$ & $\begin{array}{l}14 \\
45\end{array}$ & $\begin{array}{l}29 \\
36\end{array}$ & 29 & 17 & $\begin{array}{l}7 \\
1\end{array}$ \\
\hline Benzene & 54 & 39 & 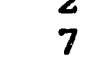 & - & - & $\begin{array}{l}45 \\
46\end{array}$ & $\begin{array}{l}36 \\
41\end{array}$ & $\begin{array}{l}14 \\
12\end{array}$ & $\begin{array}{l}4 \\
2\end{array}$ & 1 \\
\hline $\begin{array}{l}\text { Ethylbenzene } \\
\text { 1,1-Diphenyl- }\end{array}$ & 42 & 45 & 12 & 1 & - & 18 & 34 & 29 & 14 & 4 \\
\hline ethane & 40 & 43 & 15 & 3 & - & 9 & 24 & 30 & 22 & 11 \\
\hline Stilbene & 70 & 23 & 6 & - & - & 36 & 33 & 20 & 8 & 3 \\
\hline $\begin{array}{l}\text { Phenanthrene } \\
\text { Diphenyl- }\end{array}$ & & & & & & 25 & 34 & 25 & 12 & 4 \\
\hline methane & 67 & 27 & 6 & - & - & 30 & 33 & 22 & 10 & 4 \\
\hline
\end{tabular}


Table III. Aliphatic vs. Aromatic Deuterium in Products from Thermolysis of 1,2-Diphenylethane under $D_{2}$ at $450^{\circ} \mathrm{C}$ by NMR.

\begin{tabular}{lcccr}
\hline Compound & $\begin{array}{c}\text { Time } \\
\text { (min) }\end{array}$ & $\begin{array}{c}\text { Aromatic D } \\
\text { /molecule }\end{array}$ & $\begin{array}{c}\text { Aliphatic D } \\
/ \text { molecule }_{\mathrm{CH}_{2}}\end{array}$ & $\mathrm{CH}_{3}$ \\
\hline 1,2-Diphenyl- & & & & \\
ethane & 8 & 0.13 & 0.09 & \\
Toluene & 30 & 0.91 & 0.65 & 0.18 \\
Benzene & 8 & 0.17 & & 0.39 \\
Ethylbenzene & 30 & 0.65 & 0.18 & 0.54 \\
& 30 & 0.66 & 0.38 & 0.44 \\
& 15 & 0.36 & 0.50 & 0.54 \\
\hline
\end{tabular}

Figure 1. First-Order Pfot for Conversion of 1,2-Diphanylethane Under $\mathrm{D}_{2}$ at $450^{\circ} \mathrm{C}$.

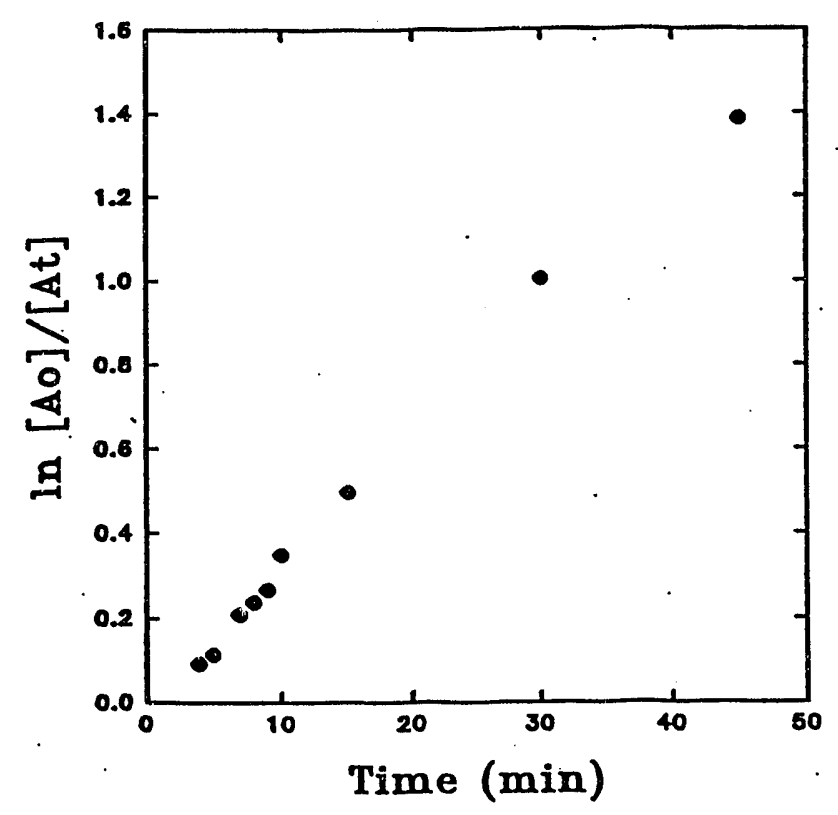

Figure 2. Glase Reaction Veseol for Thermolysis Under $\mathbf{D}_{\mathbf{2}}$.
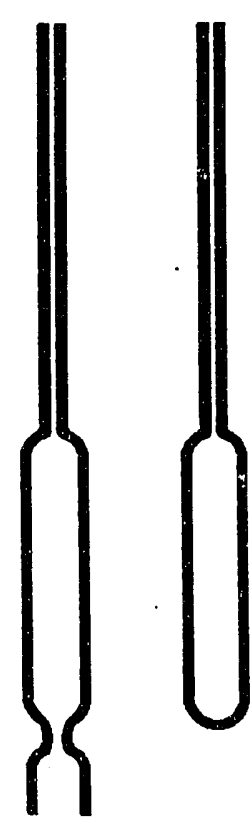

(a)

(b) 
Figure 3. Minimum Steps to Explain Deuterium Distribution Pattern

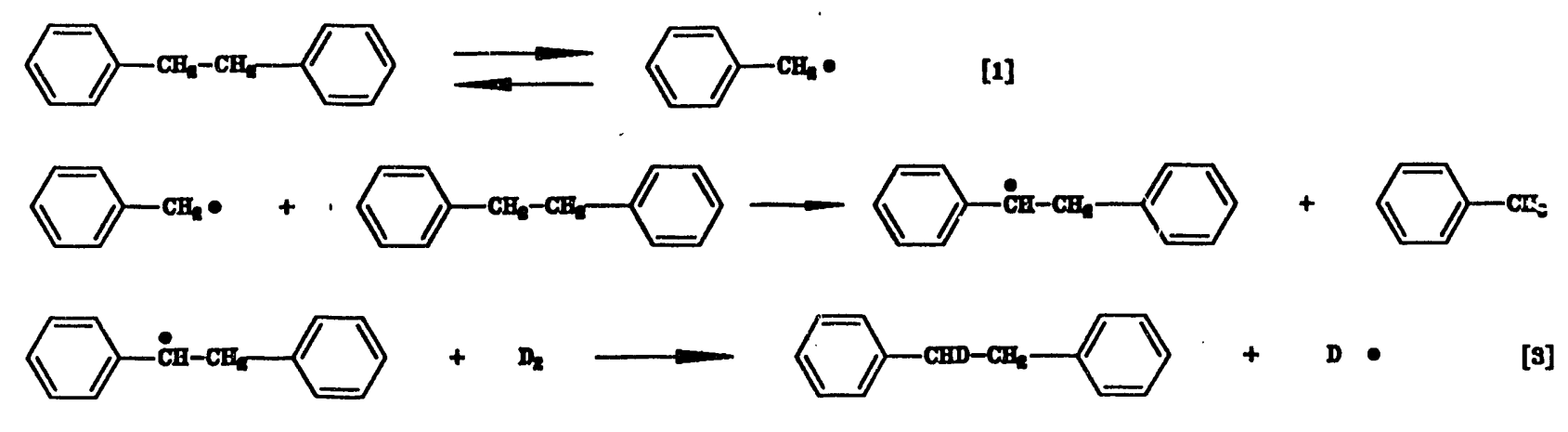
Do

(1)

(1)

$\mathrm{PhCH}_{2} \cdot+$

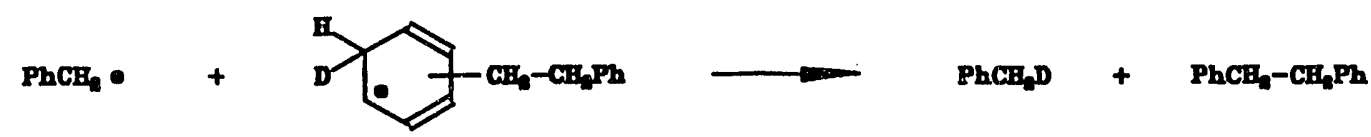

[8]

[O]

H० $+\mathrm{D}_{\mathrm{W}} \longrightarrow \mathrm{BD}+\mathrm{D} \bullet$ [10] 

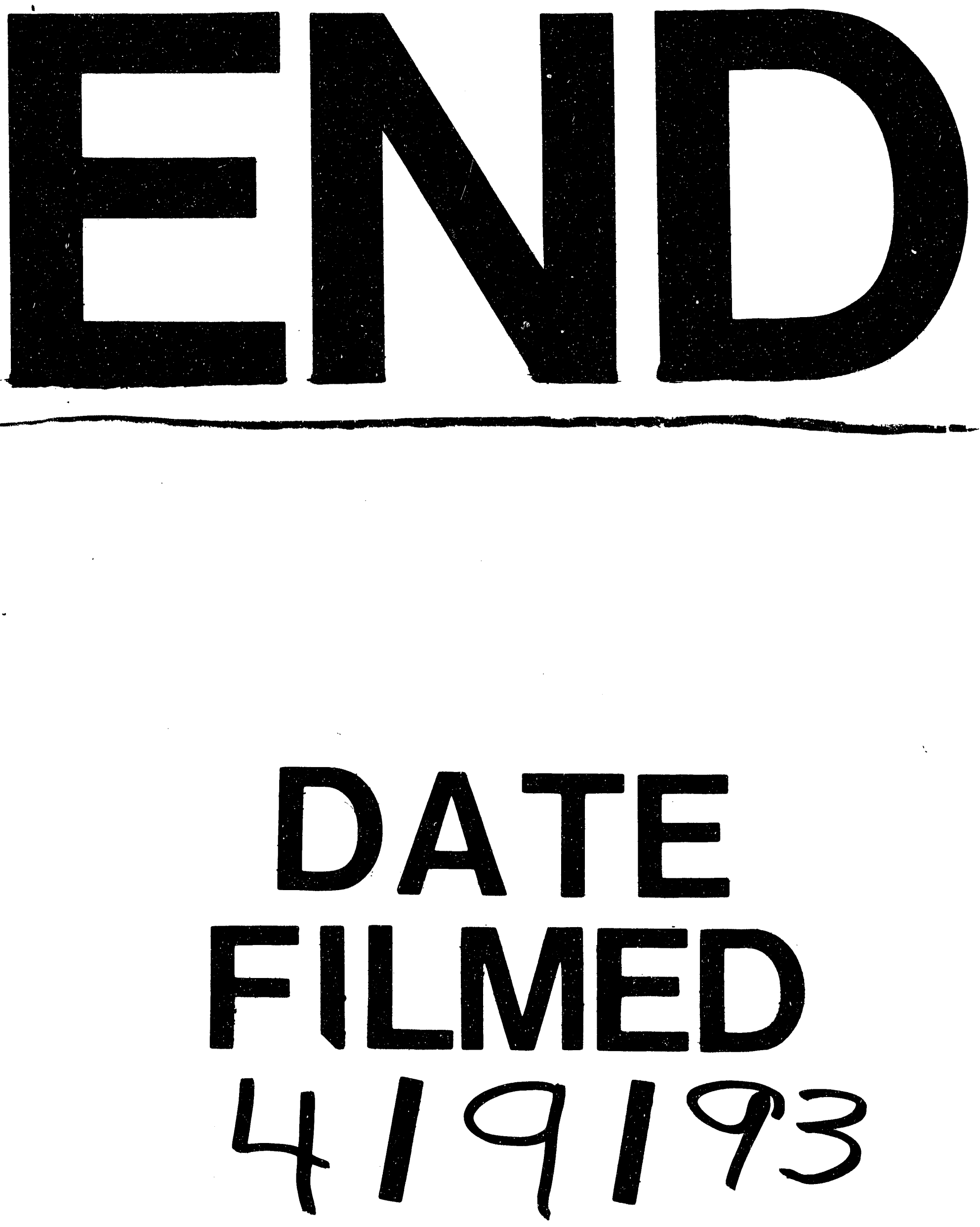
